\title{
EFEITO DA SACAROSE E SORBITOL NA CONSERVAÇÃO IN VITRO DE Passiflora giberti N. E. Brown ${ }^{1}$
}

\author{
GLÁUCIA AMORIM FARIA2; MARIA ANGÉLICA PEREIRA DE CARVALHO COSTA3; \\ TATIANA GÓES JUNGHANS ${ }^{4}$; CARLOS ALBERTO DA SILVA LEDO ${ }^{4}$; ANTÔNIO DA SILVA SOUZA ${ }^{4}$
}

\begin{abstract}
RESUMO - Este trabalho teve como objetivo estudar o efeito da sacarose e do sorbitol na conservação in vitro de um acesso de Passiflora giberti N. E. Brown. Para isso, foi instalado um experimento no delineamento inteiramente casualizado, em que foi comparado o tratamentotestemunha (MS padrão) com o meio MS suplementado com três concentrações de sacarose $\left(0 ; 15\right.$ e $\left.30 \mathrm{~g} \mathrm{~L}^{-1}\right)$ em combinação com três concentrações de sorbitol $\left(10 ; 20\right.$ e $\left.40 \mathrm{~g} \mathrm{~L}^{-1}\right)$. As avaliações foram realizadas aos 30; 60; 90 e 120 dias de incubação, observando-se o comprimento das brotações $(\mathrm{cm})$, número de raízes, número e coloração das folhas. Os resultados mostram ser possível conservar sob crescimento lento, por quatro meses, microplantas de maracujazeiro em meio de cultura MS suplementado com $10 \mathrm{ou} 20 \mathrm{~g} \mathrm{~L}^{-1}$ de sorbitol, na ausência de sacarose, e mantidas sob condições de fotoperíodo de $16 \mathrm{~h}\left(22 \mu \mathrm{E} \mathrm{m}^{-2} \mathrm{~s}^{-1}\right)$ e temperatura de $27 \pm 1{ }^{\circ} \mathrm{C}$. A sacarose promoveu maior desenvolvimento de microplantas. A rizogênese é afetada pelo sorbitol na concentração de $40 \mathrm{~g} \mathrm{~L}^{-1}$ e pela ausência de sacarose no meio de cultura.
\end{abstract}

Termos para indexação: crescimento reduzido, fontes de carbono, passifloraceae.

\section{SUCROSE AND SORBITOL EFFECT IN THE IN VITRO CONSERVATION OF Passiflora giberti N. E. Brown}

\begin{abstract}
This work objectified the study of sucrose and sorbitol effect in the in vitro conservation for Passiflora giberti N. E. Brown, access. Therefore, an experiment was conducted in a completely randomized design to compare control treatment (standard MS) to MS medium supplemented with three sucrose concentrations $\left(0,15\right.$ and $\left.30 \mathrm{~g} \mathrm{~L}^{-1}\right)$ combined with three sorbitol concentrations $\left(10,20\right.$ and $\left.40 \mathrm{~g} \mathrm{~L}^{-1}\right)$, in a total of 10 treatments with 20 replicas. The experiment evaluation was carried out at 30, 60, 90 and 120 days of incubation, whereas the height of shoots $(\mathrm{cm})$, number of roots, number and color of leaves were observed. The results showed the possibility to maintain passion-fruit microplants for a four months period under slow growth in MS medium supplemented with 10 or $20 \mathrm{~g} \mathrm{~L}^{-1}$ of sorbitol, without sucrose, and kept under 16 hours photoperiod $\left(22 \mu \mathrm{E} \mathrm{m}^{-2} \mathrm{~s}^{-1}\right)$ and temperature of $27 \pm 1^{\circ} \mathrm{C}$. Sucrose sustained the longest development of the microplants. Root formation was affected by the sorbitol in the concentration of $40 \mathrm{~g} \mathrm{~L}^{-1}$ and by the absence of sucrose in the culture medium.
\end{abstract}

Index terms: reduced growth, carbon sources, passifloraceae.

\section{INTRODUÇÃO}

As técnicas de conservação in vitro constituem-se no cultivo das coleções em laboratório, pela cultura de tecidos (Nass, 2001). Esta estratégia possibilita a manutenção de um grande número de acessos num pequeno espaço físico e livre das intempéries e riscos que existem no campo, reduz os custos, garante a manutenção da fidelidade genética, facilita a disponibilidade de material para o melhoramento genético e o intercâmbio de germoplasma.

O crescimento lento tem sido utilizado com sucesso, principalmente para a conservação de meristemas e/ou ápices meristemáticos de muitas espécies, e consiste em reduzir drasticamente o metabolismo da planta, sem afetar sua viabilidade, pela indução de estresse osmótico, redução da intensidade de luz ou temperatura, acréscimo de retardantes de crescimento e/ou diminuindo a concentração dos componentes salinos e orgânicos do meio de cultura (Withers \& Williams, 1998). Os agentes osmóticos, tais como manitol, sorbitol, sacarose, dentre outros, ao serem adicionados ao meio de cultura, atuam externamente, removendo o excesso da água intracelular, por gradiente osmótico, fazendo com que o crescimento da cultura ocorra de forma mais lenta (Dumet et al., 1993).

Este trabalho teve como objetivo estudar o efeito da sacarose e do sorbitol na conservação in vitro de Passiflora giberti N. E. Brown.

\section{MATERIAL E MÉTODOS}

Foram utilizadas como material vegetal gemas laterais de plantas de Passiflora giberti N. E. Brown, de um acesso do Banco Ativo de Germoplasma da Embrapa Mandioca e Fruticultura Tropical cultivadas in vitro, no meio de cultura MS (Murashige \& Skoog, 1962), suplementado com $30 \mathrm{~g} \mathrm{~L}^{-1}$ de sacarose (MS padrão).

Esses explantes foram inoculados em frascos tipo magenta ${ }^{\circledR}$ contendo $20 \mathrm{~mL}$ do meio de cultura MS padrão e em meio MS suplementado com a combinação de três concentrações de sorbitol (10; 20 e $\left.40 \mathrm{~g} \mathrm{~L}^{-1}\right)$ e três concentrações de sacarose $\left(0 ; 15\right.$ e $\left.30 \mathrm{~g} \mathrm{~L}^{-1}\right)$. Os meios foram solidificados com phytagel ${ }^{\circledR}\left(0,2 \mathrm{~g} \mathrm{~L}^{-1}\right)$ e pH ajustado a 5,8. As culturas foram incubadas sob fotoperíodo de $16 \mathrm{~h}\left(22 \mu \mathrm{E} \mathrm{m}^{-2} \mathrm{~s}^{-1}\right)$ e temperatura de $27 \pm 1{ }^{\circ} \mathrm{C}$.

O delineamento experimental foi o inteiramente casualizado, com 20 repetições, em esquema fatorial $3 \times 3+1$ : três concentrações de sacarose, três concentrações de sorbitol, mais uma testemunha (MS padrão), totalizando 10 tratamentos: $\mathrm{T} 1=$ Testemunha (MS padrão); $\mathrm{T} 2=0 \mathrm{~g} \mathrm{~L}^{-1}$ de sacarose $+10 \mathrm{~g} \mathrm{~L}^{-1}$ de sorbitol; $\mathrm{T} 3=0 \mathrm{~g} \mathrm{~L}^{-1} \mathrm{de}$ sacarose $+20 \mathrm{~g} \mathrm{~L}^{-1}$ de sorbitol; $\mathrm{T} 4=0 \mathrm{~g} \mathrm{~L}^{-1}$ de sacarose $+40 \mathrm{~g} \mathrm{~L}^{-1} \mathrm{de}$ sorbitol; $\mathrm{T} 5=15 \mathrm{~g} \mathrm{~L}^{-1}$ de sacarose $+10 \mathrm{~g} \mathrm{~L}^{-1}$ de sorbitol; $\mathrm{T} 6=15 \mathrm{~g} \mathrm{~L}^{-}$ ${ }^{1}$ de sacarose $+20 \mathrm{~g} \mathrm{~L}^{-1}$ de sorbitol; $\mathrm{T} 7=15 \mathrm{~g} \mathrm{~L}^{-1}$ de sacarose $+40 \mathrm{~g} \mathrm{~L}^{-}$ ${ }^{1}$ de sorbitol; $\mathrm{T} 8=30 \mathrm{~g} \mathrm{~L}^{-1}$ de sacarose $+10 \mathrm{~g} \mathrm{~L}^{-1}$ de sorbitol; $\mathrm{T} 9=30$ $\mathrm{g} \mathrm{L}^{-1}$ de sacarose $+20 \mathrm{~g} \mathrm{~L}^{-1}$ de sorbitol, e T10 $=30 \mathrm{~g} \mathrm{~L}^{-1}$ de sacarose + $40 \mathrm{~g} \mathrm{~L}^{-1}$ de sorbitol. A parcela experimental foi representada por um frasco, contendo um explante.

As avaliações do experimento foram realizadas aos 30;60; 90 e 120 dias de incubação, observando-se o comprimento das brotações (cm); número de folhas; número de raízes, e coloração das folhas. Para esta última variável, foi atribuída a seguinte escala de notas: 1folhas totalmente verdes; 2 - folhas verde-claras, e 3- folhas amareladas (início do secamento). A variável comprimento das brotações foi transformada para $\ln (\mathrm{x}+10)$ e, para as variáveis número de raízes e coloração das folhas foi utilizada a transformação de dados $\sqrt{x+0,5}$,

\footnotetext{
(Trabalho 179-2005). Recebido: 01-11-2005. Aceito para publicação: 30-05-2006.

${ }^{2}$ Professora da Faculdade de Ciência e Tecnologia Albert Einstein, Cruz das Almas, BA. Doutoranda em Agronomia da FEIS/UNESP, Av. Brasil, 56, CEP 15385000, Ilha Solteira-SP. E-mail: glauciaamorim@yahoo.com.br.

${ }^{3}$ Centro de Ciências Agrárias e Ambientais da UFBA, CEP. 44.380-000, Cruz das Almas-BA. E-mail: mapcosta@ufba.br

${ }^{4}$ Embrapa Mandioca e Fruticultura Tropical, CEP. 44.380-000, Cruz das Almas-BA, E-mail: tatiana@cnpmf.embrapa.br, ledo@cnpmf.embrapa.br, assouza@cnpmf.embrapa.br.
} 
TABELA 1 - Contrastes entre a média dos tratamentos e a testemunha para as variáveis comprimento das brotações (CB), em cm, número de folhas (NF), número de raízes (NR) e coloração das folhas (CF).

\begin{tabular}{ccccc}
\hline Contraste & CB & NF & NR & CF \\
\hline T2 T1 & $-3,6938^{*}$ & $-1,8250^{*}$ & $-1,7000^{*}$ & $-0,3208$ \\
T3 - T1 & $-3,7916^{*}$ & $-2,0731^{*}$ & $-1,6545^{*}$ & 0,1408 \\
T4 - T1 & $-3,7275^{*}$ & $-2,3125^{*}$ & $-1,7000^{*}$ & $-0,0708$ \\
T5 - T1 & $-0,7225^{*}$ & $-0,2375$ & $-1,1375^{*}$ & $-0,3003^{*}$ \\
T6-T1 & $-2,3038^{*}$ & $-0,5750$ & $-1,0125^{*}$ & $-0,3208^{*}$ \\
T7 - T1 & $-3,5857^{*}$ & $-0,8592^{*}$ & $-1,7000^{*}$ & 0,0382 \\
T8 - T1 & $-1,8225^{*}$ & $-0,2000$ & $-1,2250^{*}$ & $-0,1988$ \\
T9-T1 & $-2,1150^{*}$ & 0,1875 & $-0,7750^{*}$ & $-0,0377$ \\
T10-T1 & $-3,6575^{*}$ & $-1,3375^{*}$ & $-1,6750^{*}$ & 0,3221 \\
\hline
\end{tabular}

* significativo a $5 \%$ de probabilidade, pelo teste de Dunnett. T1 = Testemunha (MS padrão); $\mathrm{T} 2=0 \mathrm{~g} \mathrm{~L}^{-1}$ de sacarose $+10 \mathrm{~g} \mathrm{~L}^{-1} \mathrm{de} \mathrm{sorbitol;} \mathrm{T} 3=0 \mathrm{~g} \mathrm{~L}{ }^{-1}$ de sacarose $+20 \mathrm{~g} \mathrm{~L}^{-1}$ de sorbitol; $\mathrm{T} 4=0 \mathrm{~g} \mathrm{~L}^{-1}$ de sacarose $+40 \mathrm{~g} \mathrm{~L}^{-1}$ de sorbitol; $\mathrm{T} 5=15 \mathrm{~g} \mathrm{~L}^{-1}$ de sacarose $+10 \mathrm{~g} \mathrm{~L}^{-1}$ de sorbitol; $6=15 \mathrm{~g} \mathrm{~L}-1$ de sacarose +20 $\mathrm{g} \mathrm{L}^{-1}$ de sorbitol; $\mathrm{T} 7=15 \mathrm{~g} \mathrm{~L}^{-1}$ de sacarose $+40 \mathrm{~g} \mathrm{~L}^{-1}$ de sorbitol; $\mathrm{T} 8=30 \mathrm{~g} \mathrm{~L}^{-1}$ de sacarose $+10 \mathrm{~g} \mathrm{~L}^{-1}$ de sorbitol; $\mathrm{T} 9=30 \mathrm{~g} \mathrm{~L}^{-1}$ de sacarose $+20 \mathrm{~g} \mathrm{~L}^{-1}$ de sorbitol, e $\mathrm{T} 10=30 \mathrm{~g} \mathrm{~L}^{-1}$ de sacarose $+40 \mathrm{~g} \mathrm{~L}^{-1}$ de sorbitol.

visando ao atendimento das pressuposições da análise de variância. Foi aplicado o teste de Dunnet, a $5 \%$ de probabilidade, para a comparação da média dos tratamentos em relação à média da testemunha. Para a comparação das médias, foi aplicado o teste de Tukey, a 5\% de probabilidade. As análises estatísticas foram realizadas utilizando o programa estatístico SAS - Statistical Analysis System (SAS Institute, 2000).

\section{RESULTADOS E DISCUSSÃO}

Não houve efeito significativo da interação sacarose $x$ sorbitol e da interação tripla entre os fatores estudados para as variáveis número de raízes e número de folhas $(\mathrm{P} \geq 0,05)$, sendo que, para esta última variável, a interação sorbitol x avaliação também não foi significativa $(\mathrm{P} \geq 0,05)$. Para a coloração das folhas, só houve significância para sorbitol e a interação sacarose $\mathrm{x}$ avaliação $(\mathrm{P}<0,05)$.

$\mathrm{O}$ crescimento e o desenvolvimento das microplantas foram influenciados significativamente pelos açúcares. Observa-se, pela
Tabela 1, que todos os tratamentos apresentaram comprimento das brotações e número das raízes menor que a testemunha $(\mathrm{P}<0,05)$. Nos tratamentos com $0 \mathrm{~g} \mathrm{~L}^{-1}$ de sacarose combinado com $20 \mathrm{~g} \mathrm{~L}^{-1}$ de sorbitol e $0 \mathrm{~g} \mathrm{~L}^{-1}$ de sacarose combinado com $40 \mathrm{~g} \mathrm{~L}^{-1}$ de sorbitol, as microplantas apresentaram menor comprimento, número de folhas e número de raízes. $\mathrm{O}$ tratamento com $30 \mathrm{~g} \mathrm{~L}^{-1}$ de sacarose e $20 \mathrm{~g} \mathrm{~L}^{-1} \mathrm{de}$ sorbitol promoveu a formação de maior número de folhas do que a testemunha, embora essa diferença não tenha sido significativa $\left(\mathrm{P}^{3} 0,5\right)$. Os tratamentos com $20 \mathrm{~g} \mathrm{~L}^{-1}$ de sorbitol, na presença de sacarose, foram os que induziram maior número de raízes. Os tratamentos $15 \mathrm{~g} \mathrm{~L}^{-}$ ${ }^{1}$ de sacarose, combinado com 10 e $20 \mathrm{~g} \mathrm{~L}^{-1}$ de sorbitol, foram os que alcançaram os menores valores para coloração das folhas, indicando maior número de folhas verdes.

Na Tabela 2, observa-se que, para a variável comprimento das brotações, os menores valores foram obtidos com a utilização de 10 ou $20 \mathrm{~g} \mathrm{~L}^{-1}$ de sorbitol na ausência de sacarose. Dentre as microplantas cultivadas nos tratamentos com utilização simultânea de sorbitol e sacarose, as supridas com $40 \mathrm{~g} \mathrm{~L}^{-1}$ de sorbitol

TABELA 2 - Valores médios para comprimento das brotações $(\mathrm{cm})$, número de folhas, número de raízes, coloração das folhas em função das concentrações de sacarose e sorbitol $\left(\mathrm{g} \mathrm{L}^{-1}\right)$.

\begin{tabular}{|c|c|c|c|c|}
\hline \multirow{2}{*}{ Sacarose } & \multicolumn{3}{|c|}{ Sorbitol } & \multirow{2}{*}{ Média } \\
\hline & 10 & 20 & 40 & \\
\hline \multicolumn{5}{|c|}{ Comprimento das brotações } \\
\hline 0 & $1,2213 \mathrm{~A} \mathrm{~b}$ & $1,1234 \mathrm{~A} \mathrm{~b}$ & $1,1875 \mathrm{~A} \mathrm{a}$ & $1,1813 \mathrm{~b}$ \\
\hline 15 & $4,1925 \mathrm{~A} \mathrm{a}$ & $2,6113 \mathrm{~B} \mathrm{a}$ & $1,3293 \mathrm{~B} \mathrm{a}$ & $2,7404 \mathrm{a}$ \\
\hline 30 & $3,0925 \mathrm{~A} \mathrm{a}$ & $2,8000 \mathrm{~A} \mathrm{a}$ & $1,2575 \mathrm{~B} \mathrm{a}$ & $2,3833 \mathrm{a}$ \\
\hline Média & $2,8354 \mathrm{~A}$ & $2,2536 \mathrm{~B}$ & $1,2566 \mathrm{C}$ & 2,1182 \\
\hline Testemunha & & & & 4,9150 \\
\hline \multicolumn{5}{|c|}{ Número de folhas } \\
\hline 0 & $0,6875 \mathrm{~A} \mathrm{~b}$ & $0,4394 \mathrm{~A} \mathrm{~b}$ & $0,2000 \mathrm{~A} \mathrm{~b}$ & $0,4425 \mathrm{~b}$ \\
\hline 15 & $2,2750 \mathrm{~A} \mathrm{a}$ & $1,9375 \mathrm{~A} \mathrm{a}$ & $1,6533 \mathrm{~A} \mathrm{a}$ & $1,9617 \mathrm{a}$ \\
\hline 30 & $2,3125 \mathrm{AB}$ a & $2,7000 \mathrm{~A} \mathrm{a}$ & $1,1750 \mathrm{~B} \mathrm{ab}$ & $2,0625 \mathrm{a}$ \\
\hline Média & $1,7583 \mathrm{~A}$ & $1,7699 \mathrm{~A}$ & $0,9957 \mathrm{~B}$ & 1,6095 \\
\hline Testemunha & & & & 2,5125 \\
\hline \multicolumn{5}{|c|}{ Número de raízes } \\
\hline 0 & $0,0000 \mathrm{~A} \mathrm{a}$ & $0,0455 \mathrm{~A} \mathrm{~b}$ & $0,0000 \mathrm{~A} \mathrm{a}$ & $0,0133 \mathrm{~b}$ \\
\hline 15 & $0,5625 \mathrm{AB}$ a & $0,6875 \mathrm{~A} \mathrm{a}$ & $0,0000 \mathrm{~B} \mathrm{a}$ & $0,4255 \mathrm{a}$ \\
\hline 30 & $0,4750 \mathrm{AB}$ a & $0,9250 \mathrm{~A} \mathrm{a}$ & $0,0250 \mathrm{~B} \mathrm{a}$ & $0,4750 \mathrm{a}$ \\
\hline Média & $0,3458 \mathrm{AB}$ & $0,5841 \mathrm{~A}$ & $0,0085 \mathrm{~B}$ & 0,4520 \\
\hline Testemunha & & & & 1,7000 \\
\hline \multicolumn{5}{|c|}{ Coloração das folhas } \\
\hline 0 & $1,0000 \mathrm{~A} \mathrm{a}$ & $1,4615 \mathrm{~A} \mathrm{a}$ & $1,2500 \mathrm{~A} \mathrm{a}$ & $1,2188 \mathrm{a}$ \\
\hline 15 & $1,0204 \mathrm{~B} \mathrm{a}$ & $1,0000 \mathrm{~B} \mathrm{~b}$ & $1,3590 \mathrm{~A} \mathrm{a}$ & $1,1163 \mathrm{a}$ \\
\hline 30 & $1,1220 \mathrm{~B} \mathrm{a}$ & $1,2830 \mathrm{~B} \mathrm{ab}$ & $1,6429 \mathrm{~A} \mathrm{a}$ & $1,3115 \mathrm{a}$ \\
\hline Média & $1,0571 \mathrm{~B}$ & $1,1963 \mathrm{~B}$ & $1,4648 \mathrm{~A}$ & 1,2292 \\
\hline Testemunha & & & & 1,3208 \\
\hline
\end{tabular}

Médias seguidas pela mesma letra minúscula nas colunas e maiúsculas nas linhas não diferem estatisticamente entre si, pelo teste de Tukey, a 5\% de probabilidade. 
apresentaram os menores comprimentos. Os meios de cultura suplementados com 15 e $30 \mathrm{~g} \mathrm{~L}^{-1}$ de sacarose, combinados com 10 e 20 $\mathrm{g} \mathrm{L}^{-1}$ de sorbitol, proporcionaram maiores comprimentos das brotações. Estes dados indicam que a presença da sacarose no meio de cultivo foi fundamental para manter o desenvolvimento das plantas.

Para a cultura de Prunus cerasus L., os açúcares sacarose, glicose, frutose e sorbitol favoreceram o crescimento quando as suas concentrações estavam entre $20 \mathrm{~g} \mathrm{~L}^{-1}$ e $30 \mathrm{~g} \mathrm{~L}^{-1}$ (Borkowska \& Szczerba, 1991). Contudo, de acordo com George (1993), o sorbitol usualmente não é metabolizado pelas plantas, e sua atuação freqüentemente está relacionada em modificar o potencial osmótico do meio de cultura. De acordo com Mello et al. (2001), o sorbitol foi ineficiente para o crescimento in vitro de Bauhinia forficata L., Curcuma zedoaria e Phaseolus vulgaris L.

Com relação ao número de folhas emitidas, independentemente da concentração de sorbitol utilizada, os maiores valores foram obtidos quando se utilizou sacarose no meio. A maior concentração de sacarose, combinada com a adição de $40 \mathrm{~g} \mathrm{~L}^{-1}$ de sorbitol, promoveu a formação de um menor número de folhas (Tabela 2).
Os tratamentos com sacarose no meio de cultivo favoreceram o desenvolvimento de raízes, com exceção daqueles combinados com $40 \mathrm{~g} \mathrm{~L}^{-1}$ de sorbitol (Tabela 2). Santana (2003), estudando os fatores que afetam o enraizamento in vitro em brotações e estacas de Annona glabra L., verificou que os maiores percentuais de enraizamento ocorreram em meio de cultura suplementado com $20 \mathrm{~g} \mathrm{~L}^{-1}$ de sacarose. Faria \& Segura (1997) obtiveram altas taxas de enraizamento para espécie Passiflora edulis f. flavicarpa em meio MS suplementado com $30 \mathrm{~g} \mathrm{~L}^{-1}$ de sacarose. Veierskov et al. (1982) relatam que altas concentrações de carboidrato no meio de cultura têm um efeito negativo sobre o enraizamento, devido ao acúmulo de açúcar acima dos níveis fisiológicos nos tecidos.

Com relação à qualidade da microplanta, medida pela coloração das folhas, verificou-se que, na ausência de sacarose, não houve efeito das diferentes concentrações de sorbitol. Contudo, nas concentrações de 15 e $30 \mathrm{~g} \mathrm{~L}^{-1}$ de sacarose, as microplantas apresentaram o melhor vigor quando supridas com 10 e $20 \mathrm{~g} \mathrm{~L}^{-1} \mathrm{de}$ sorbitol.

Santana (2003), utilizando como fonte de carbono sacarose,
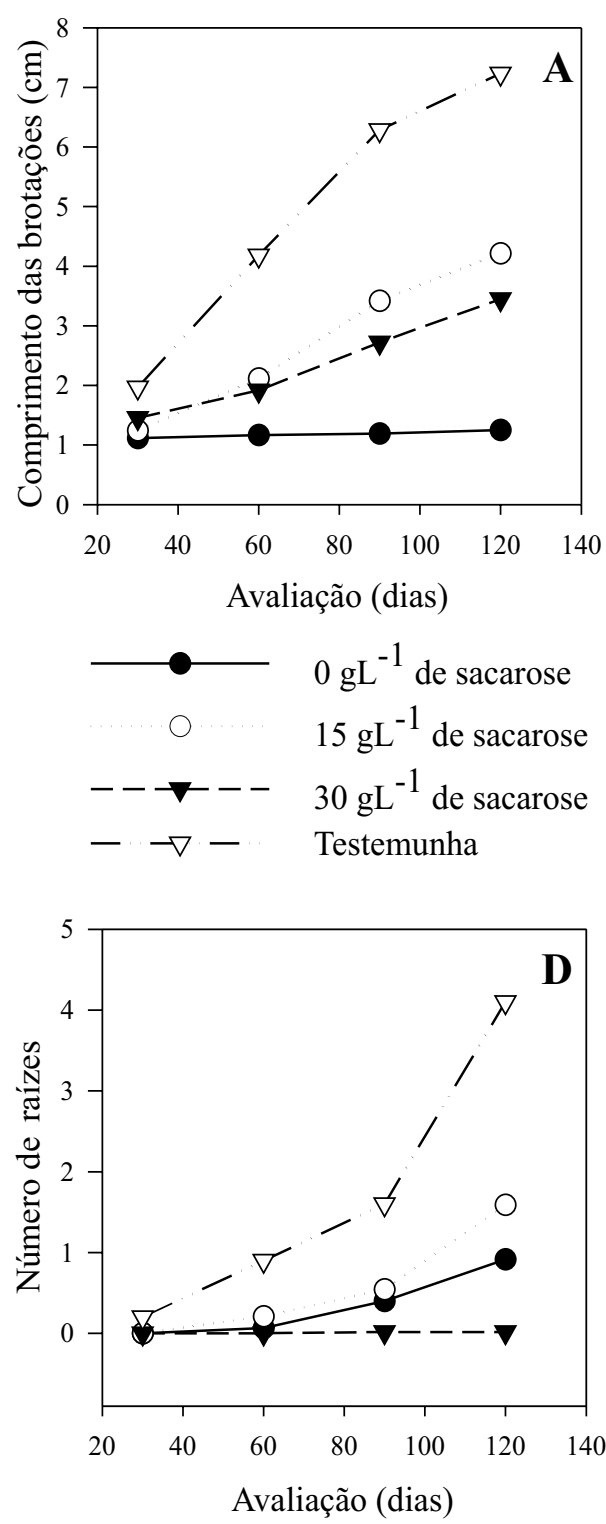

$10 \mathrm{gL}^{-1}$ de sorbitol

. O...... $20 \mathrm{gL}^{-1}$ de sorbitol

$--\nabla---40 \mathrm{gL}^{-1}$ de sorbitol

$-\nabla-\cdots \quad$ Testemunha
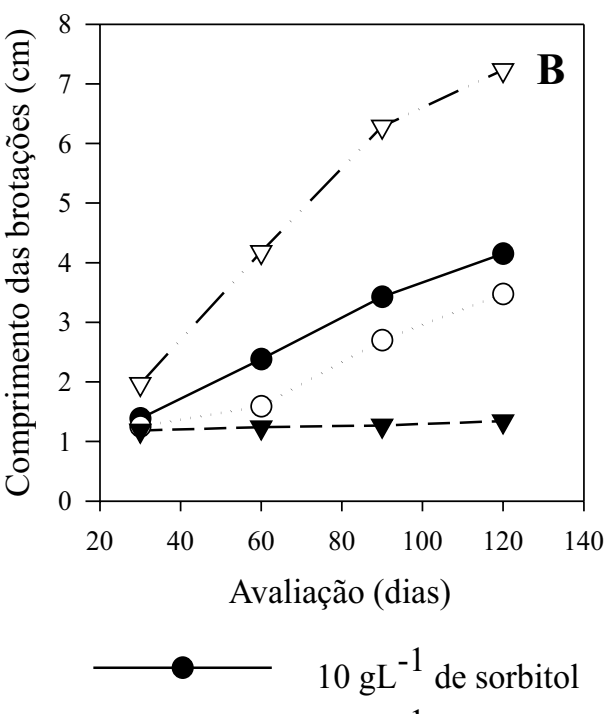

$20 \mathrm{gL}^{-1}$ de sorbitol

$--\rightarrow---40 \mathrm{gL}^{-1}$ de sorbitol

$-\rightarrow-\quad$ Testemunha
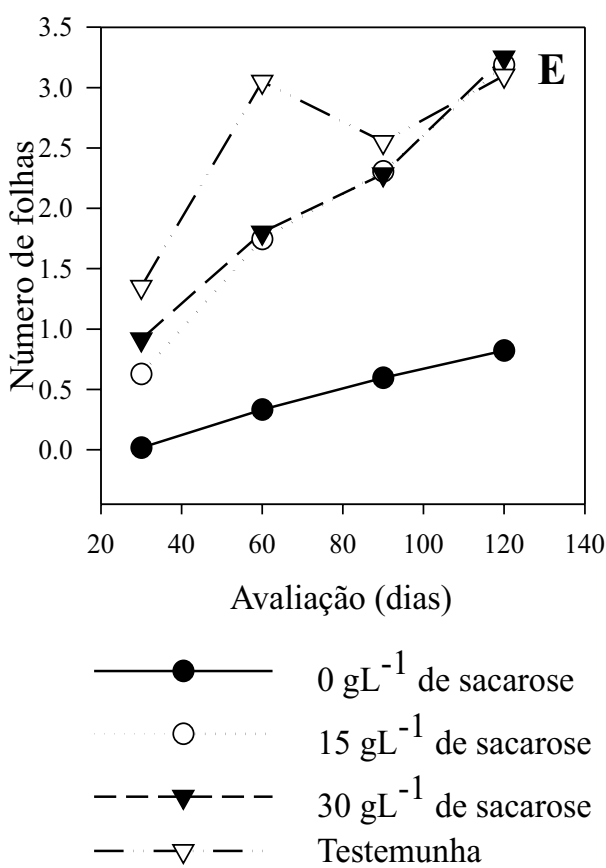
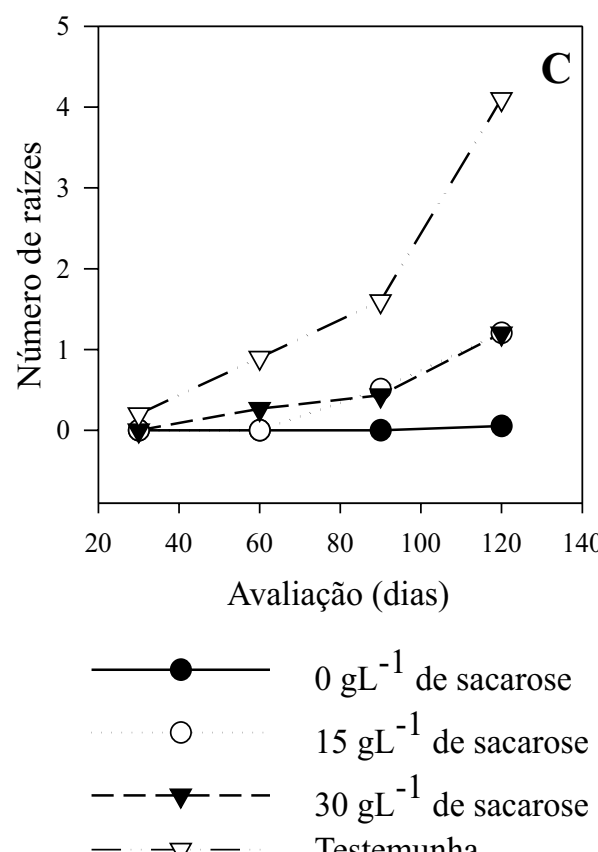

$-\rightarrow-\quad$ Testemunha

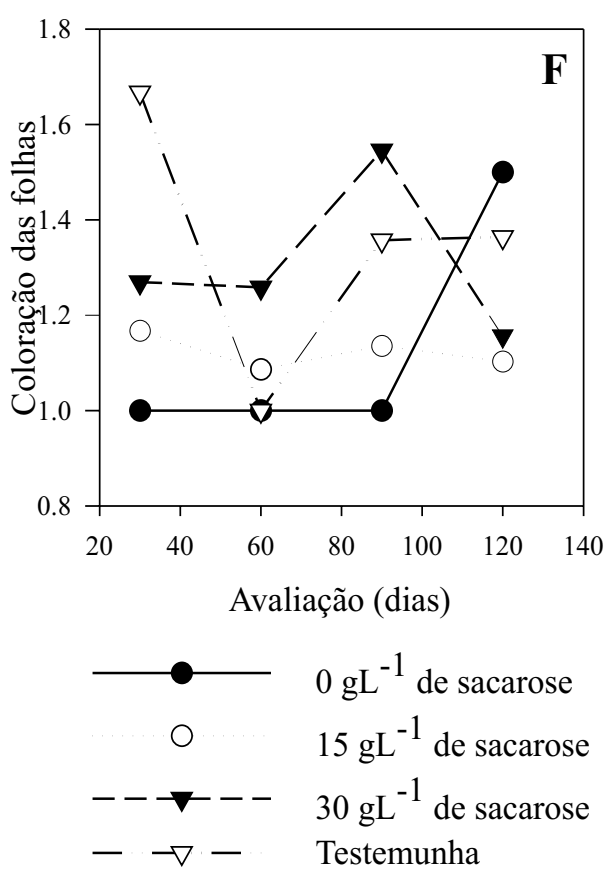

FIGURA 1 - Comprimento das brotações, em cm, em função das concentrações de sacarose (A) e de sorbitol (B); número de raízes em função das concentrações de sacarose (C) e de sorbitol (D); número de folhas (E), e coloração das folhas (F) em função das concentrações de sacarose, ao longo dos períodos de avaliação, em dias. 
glicose, frutose, galactose, maltose e sorbitol no cultivo in vitro de Anonáceas, evidenciou que as menores taxas de desenvolvimento das microplantas ocorreu no tratamento com sorbitol. Al-Kharyri \& Al-Bahirani (2002) relataram baixas taxas de desenvolvimento de calos de arroz na presença de $30 \mathrm{~g} \mathrm{~L}^{-1}$ de sorbitol. Lemos \& Baker (1998) verificaram que a maltose, sorbitol, frutose e polietileno glicol, adicionados ao meio de cultura, não favoreceram o desenvolvimento das brotações de gravioleira, enquanto a sacarose, galactose e glicose induziram a formação de brotações adventícias nos explantes. Segundo Grattapaglia \& Machado (1998), a sacarose é a fonte de carbono mais utilizada nos protocolos de cultivo in vitro, sendo considerada a melhor fonte para a diferenciação celular e o desenvolvimento das microplantas. Em geral, a concentração de $30 \mathrm{~g}$ $\mathrm{L}^{-1}$ sustenta o desenvolvimento de brotações para a grande maioria das espécies já estabelecidas in vitro.

$\mathrm{O}$ tratamento-testemunha apresentou as maiores taxas de crescimento e desenvolvimento radicular com valores superiores aos demais tratamentos, ao longo dos 120 dias de avaliação (Figura 1). A utilização dos tratamentos com $0 \mathrm{~g} \mathrm{~L}^{-1}$ de sacarose e de $40 \mathrm{~g} \mathrm{~L}^{-1}$ de sorbitol promoveu as menores taxas de crescimento das brotações (Figura 1A e 1B) e as menores taxas de emissão de raízes (Figura 1C e 1D) e folhas (Figuras 1E).

As brotações oriundas do tratamento com $15 \mathrm{~g} \mathrm{~L}^{-1}$ de sacarose praticamente mantiveram uniformidade na coloração das folhas, com a predominância de folhas verdes, enquanto no meio suplementado com $30 \mathrm{~g} \mathrm{~L}^{-1}$ de sacarose, aos 90 dias, predominaram folhas verdeclaras e, a partir de então, houve predominância de folhas com coloração totalmente verde. Possivelmente, este fato tenha ocorrido devido à expansão de novas folhas. Comportamento contrário foi verificado na ausência de sacarose no meio (Figura 1F).

Os resultados obtidos neste trabalho mostraram ser viável a manutenção de crescimento lento do maracujazeiro por um período de quatro meses.

\section{CONCLUSÕES}

1) É possível conservar sob crescimento lento, por quatro meses, microplantas de maracujazeiro em meio de cultura MS suplementado com 10 ou $20 \mathrm{~g} \mathrm{~L}^{-1}$ de sorbitol, na ausência de sacarose.

2) É possível conservar sob crescimento reduzido com bom desenvolvimento radicular e número de folhas em meio de cultura MS suplementado com $15 \mathrm{~g} \mathrm{~L}^{-1}$ de sacarose e $20 \mathrm{~g} \mathrm{~L}^{-1}$ de sorbitol.

3) A sacarose promoveu maior desenvolvimento de microplantas.

4) A rizogênese é afetada pelo álcool açúcar sorbitol na concentração de $40 \mathrm{~g} \mathrm{~L}^{-1}$ e pela ausência de sacarose no meio de cultura.

\section{REFERÊNCIAS}

AL-KHARYRI, J.M.; AL-BAHIRANI, A.M. Callus growth and proline accumulation in response to sorbitol and sucrose-induced osmotic stress in rice. Biologia Plantarum. Dordrecht, v. 45, n.4, p. 609 $611,2002$.
BORKOWSKA, B.; SZCZERBA, J. Influence of different carbon sources on invertase activity and growth of sour cherry (Prunus cerasus L.) shoot cultures. Journal of Experimental Botany, Oxford, v. 42, n. 240, p. 911-915, 1991.

DUMET, D; ENGELMANN, F.; CHABRILLANGE, N.; DUVAL, Y.; DEREUDDRE, J. Importance of sourse for the acquisition of tolerance to desiccation and cryopreservation of oil palm somatic embryos. Cryo-Letters, London, n. 14, p. 243-250, 1993.

FARIA, J.L.C.; SEGURA, J. In vitro control of adventitious bud differentiation by inorganic medium components and silver thiosulfate in explants of Passiflora edulis f. flavicarpa. In vitro cellular \& developmental biology-plant, Columbia, v. 33, n. 3, p. 209-212, 1997.

GEORGE, F.E. The components of culture media. In GEORGE, F. E.(Ed). Plant propagation by tissue culture. London: Exegetics, 1993. p. 273-343.

GRATTAPAGLIA, D.; MACHADO, M.A. Micropropagação. In: TORRES, A.C.; CALDAS, L.S.; BUSO, J.A. (Ed). Cultura de tecidos e transformação genética de plantas. Brasília: Embrapa-SPI: Embrapa-CNPH, 1998. v.1, p.183-260.

LEMOS, E.E.P.; BAKER, D. Shoot regeneration in response to carbon source on internodal explants of Annona muricata L. Plant Growth Regulation, Dordrecht, v. 25, p. 105-112, 1998.

MELLO, O.M.; DIAS, C.T.S.D.; AMARAL, A.F.C.; MELO M. Growth of Bauhinia forficata Link, Curcuma zedoaria Roscoe and Phaseolus vulgaris L. cell suspension culture whith carbon sources. Sciencia Agrícola, Piracicaba, v. 58, n. 3, p. 1-11, sept. 2001.

MURASHIGE, T.; SKOOG, F. A revised medium for rapid growth and bioassays with tobacco tissue culture. Physiologia Plantarum, Copenhagen, v. 15, p. 437-497, 1962.

NASS, L.L. Utilização de recursos genéticos vegetais no melhoramento. In: NASS, L.L.; VALOIS, A.C.C.; MELO, I. S. de, VALADARES-INGLIS, M.C. (Ed). Recursos genéticos e melhoramento de plantas. Rondonópolis: Fundação MT, 2001.p. 30-55.

SANTANA, J.R.F. de. Controle da morfogênese in vitro em algumas espécies de annonaceae. 2003. 237f. Tese (Doutorado) Universidade Federal de Lavras, Lavras, 2003.

SAS INSTITUTE. SAS/STAT User's Guide. v. 8.0. Cary NC: SAS Institute, 2000. v.1.

VEIERSKOV, B.; ANDERSEN, A.S.; ERIKSEN, E.N. Dynamics of extractable carbohydrates in Pisum sativum. 1- Carbohydrate and nitrogen content in peã plants and cuttings grown at two different irradiances. Physiologia Plantarum, Copenhagen, v. 55, n.2, p. 167-173, 1982.

WITHERS, L.A.; WILLIAMS J.T. Conservação in vitro de recursos genéticos de plantas. In: TORRES, C.A.; CALDAS, L.S.; BUSO, J.A. (Ed). Cultura de tecidos e transformação genética de plantas. Brasília: Embrapa - SPI: Embrapa, CNPH, 1998. v.1 p. 297-329. 